\title{
Association between Osteoporosis and Metabolic Syndrome in Postmenopausal Women
}

\author{
S. M. Muraduzzaman, S. Begum, A. Siddika, A. Islam, S. Sultana, U. S. Mili, \\ M. Saiedullah, and F. Alam
}

\section{ABSTRACT}

The risk of osteoporosis is higher in elderly and postmenopausal women. Several studies in different populations investigated the association between osteoporosis and metabolic syndrome (MS); however, the results are conflicting. In our population, no study has yet been conducted to evaluate this relationship in postmenopausal women. The aim of the study was to determine the relationship between osteoporosis and metabolic syndrome in postmenopausal women. In this study, a total of 131 postmenopausal women were included. Clinical history and anthropometric data were recorded and subjected to blood collection and scan for bone mineral density (BMD) and T-score at the lumbar spine and femoral neck and by dual-energy $x$-ray absorptiometry (DEXA). Osteoporosis and osteopenia were defined from $T$-score. The lipid profile was estimated by standard spectrophotometric methods. The mean \pm SD of age (years) of the postmenopausal women was 57.0 \pm 8.4. Bone mineral densities $\left(\mathrm{g} / \mathrm{cm}^{2}\right)$ were $0.78 \pm 0.17,0.75 \pm 0.16,0.72 \pm 0.16$ and $\mathrm{T}$-scores were $2.32 \pm 1.54,-1.52 \pm 1.29,-1.53 \pm 1.39$ respectively in lumbar spine, right femoral neck and left femoral neck. Osteoporosis and osteopenia were found in $58(44.3 \%)$ and $45(34.4 \%)$ study subjects, respectively. Eightythree $(63.4 \%)$ of the study subjects have metabolic syndrome (MS). On multiple regression analysis, considering BMD at lumbar spine, right femoral neck or left femoral neck as dependent variable and age, body mass index (BMI), and MS as independent variables, $\beta$ values for MS with BMD were $-0.041(p=0.184), 0.002(p=0.938), 0.011(p=0.688)$ and with T-score were $-0.330(p=0.241),-0.005(p=0.984), 0.151(p=0.599)$ at lumbar spine and right femoral neck and left femoral neck respectively. The coefficient of osteoporosis with MS in multiple logistic regression analysis was $\beta=1.311,(p=0.003)$. In conclusion, osteoporosis is found to be positively associated with metabolic syndrome in postmenopausal women.

Keywords: Bone mineral density, metabolic syndrome, osteoporosis, postmenopause,
Published Online: November 26, 2021

ISSN: $2736-5476$

DOI:10.24018/ejclinicmed.2021.2.6.147

S. M. Muraduzzaman

Department of Biomedical Engineering \& Medical Physics, Bangladesh University of Health Sciences (BUHS), Dhaka, Bangladesh.

(e-mail: projuktimurad@gmail.com) S. Begum

Department of Applied Laboratory Sciences, Bangladesh University of Health Sciences (BUHS), Dhaka, Bangladesh.

(e-mail: shahnajbegum0002@gmail.com) A. Siddika

Department of Applied Laboratory Sciences, Bangladesh University of Health Sciences (BUHS), Dhaka, Bangladesh.

(e-mail: ashaislam174@gmail.com)

A. Islam

Department of Applied Laboratory Sciences, Bangladesh University of Health Sciences (BUHS), Dhaka, Bangladesh.

(e-mail: amirulislam3182@gmail.com) S. Sultana

National Institute of Nuclear Medicine \& Allied Sciences, Bangladesh Atomic Energy Commission, Dhaka,

Bangladesh.

(e-mail: sadias1964@gmail.com)

U. S. Mili

Bangladesh Institute of Health Sciences (BIHS), Dhaka, Bangladesh.

(e-mail: sadiamili75@yahoo.com)

M. Saiedullah*

Department of Biochemistry \& Cell Biology, and Dept of Applied Laboratory Sciences, BUHS, Dhaka, Bangladesh.

(e-mail: md.saiedullah@gmail.com)

F. Alam

Department of Radiology and Imaging Technology, Bangladesh University of Health Sciences (BUHS), Dhaka, Bangladesh.

(e-mail: vc@buhs.ac.bd)

*Corresponding Author

\section{INTRODUCTION}

During the last few decades, rapid urbanization is accompanied by distinct and measurable changes in dietary intake habits, changes in physical activity, as well as sociopsychological behavioral patterns in the Bangladeshi population [1]. These changes may adversely affect public health, resulting in the increased risk of developing type 2 
diabetes mellitus (T2DM), obesity and hypertension, and the development of metabolic syndrome (MS) [2]. Among the chronic diseases, MS is one of the most widespread throughout the world and associated with higher mortality in developed countries [3]. In Bangladesh, the prevalence of MS is high with the rising trend, which is found to be more in females compared to males ( $32 \%$ vs $25 \%$ ) [4]. Generally, MS increases the mortality rate by two times and the risk of heart attack or a stroke around three times in adults compared to people without MS [5].

Metabolic changes are physiological phenomena associated with hormonal shifts during menopause and aging [6]. In postmenopausal Bangladeshi women, MS is 1.78 times higher than premenopausal women [6]. The components of MS i.e., hypertension, diabetes mellitus, dyslipidemia is reported to be higher in postmenopausal women compared to premenopausal women [6]. During menopause, the changes in the estrogen/androgen ratio led to endothelial dysfunction, increased endothelin secretion, and decreased nitric oxide production, resulting in heightened oxidative stress, renal vasoconstriction and ultimately hypertension [7]. The tendency in developing hypertension also attributed owing to the changes in the estrogen/androgen ratio also results in increased body mass index (BMI) that also contribute to oxidative stress triggering renal vasoconstriction [7] and sympathetic activation, further increasing renin release leading to increase in angiotensin II which causes renal vasoconstriction ultimately the development of hypertension [7].

Postmenopausal women were found to have a deficiency of vitamin D [8] and reported to be linked with a decrease in bone mineral density (BMD) [9]-[11]. Bone Mineral Density (BMD) is a measure of calcium and other minerals in the bone that is attributed to exert its strength. Low BMD leads to osteopenia or osteoporosis in adults, which leads to bone loss by increased bone turnover. Around 35\% of postmenopausal women were found to lose a significant amount of bone mineral density during the postmenopausal transition period [12]. Since MS is affecting postmenopausal women at a higher rate and at this age they are subjected to osteoporotic changes, evaluation of the bone mineral density of these women is assumed to generate important data in exploring their health status and taking necessary measures in prevention. Studies on different nationals so far demonstrated conflicting results. The study involving Korean postmenopausal women with MS was found to be associated with higher BMD [13]. However, other studies reported an inverse association between BMD and MS in the Japanese and white population [14], [15].

On the other hand, [16] reported a lack of association between MS and BMD in the US population. There is a growing number of older people and a substantial proportion of them are postmenopausal women. Those are at risk of developing metabolic disorders and depleted bone mineral density. Extreme variability has been observed regarding MS and BMD in different populations. Considering the facts mentioned above, investigating the relationship of MS and BMD in postmenopausal women merits the public health interest.

\section{Materials AND Methods}

In this cross-sectional study, 131 postmenopausal women were included. After obtaining informed consent, clinical history (diabetes and hypertension) and anthropometric (age, gender, height, weight, waist circumference) data were recorded and subjected to scan for BMD by dual-energy absorptiometry, DEXA [17], [18] at the National Institute of Nuclear Medicine \& Allied Sciences, Dhaka, Bangladesh. BMD was determined at the lumbar spine, right and left femoral neck, and results are expressed as $\mathrm{g} / \mathrm{cm}^{2}$ and T-score according to WHO guidelines [19]. Osteoporosis and osteopenia were defined according to T-scores [20].

Blood samples from the participants were collected in the next morning following 10 to 12 hours of fasting and having a normal diet during the last three days; aliquots of serum and plasma were stored at $-20^{\circ} \mathrm{C}$ until biochemical analysis. Serum lipid profiles (total cholesterol, triglycerides, and highdensity lipoprotein cholesterol) were measured by spectrophotometric methods using Dimension ${ }^{\circledR}$ RxL Max chemistry system (Siemens Healthcare Diagnostics Inc. USA) using reagents (Siemens Healthcare Diagnostics Inc. USA). Serum low-density lipoprotein (LDL) cholesterol was calculated by the Friedewald formula [21].

Hypertension was defined if blood pressure $\geq 140 \mathrm{mmHg}$ and/or $\geq 90 \mathrm{mmHg}$, and/or subjects taking antihypertensive medication [3]. Diabetes (DM) was defined according to WHO guidelines (fasting plasma glucose $\geq 7.0 \mathrm{mmol} / \mathrm{L}$ ) [22]. MS was defined according to IDF [23]. The body mass index (BMI) of the subjects was calculated in $\mathrm{kg} / \mathrm{m}^{2}$ using the standard formula. BMI $=$ Weight $(\mathrm{kg}) /[\text { Height }(\mathrm{m})]^{2}$.

\section{RESULTS}

\section{A. Characteristics of the Study Subjects}

The mean \pm SD of the age of the study subjects was $57.0 \pm 8.4$ years. Among the subjects, 75 (57.3\%) were hypertensive, and $41(31.3 \%)$ were diabetic (Table I). The mean $\pm \mathrm{SD}$ of $\mathrm{BMI}$ was $26.0 \pm 4.8 \mathrm{Kg} / \mathrm{m}^{2}$ among them 49 (37.4\%) subjects were overweight (BMI: $25-30 \mathrm{~kg} / \mathrm{m}^{2}$ ) and $23(17.6 \%)$ subjects were obese $\left(\mathrm{BMI}>30 \mathrm{~kg} / \mathrm{m}^{2}\right)$. Most of the study subjects $73(48.7 \%)$ were within the age group 56-65 years, followed by $46-5554(36.0 \%)$ and $66-8521(14.0 \%)$ years; the age distribution rejects normal distribution $(\mathrm{p}=$ 0.049).

TABLE I: CHARACTERISTICS OF THE STUDY SUBJECTS

\begin{tabular}{cc}
\hline \hline Variables & Mean $\pm \mathrm{SD} / \%$ \\
\hline \hline Age (years) & $57.0 \pm 8.4$ \\
BMI $\left(\mathrm{kg} / \mathrm{m}^{2}\right)$ & $26.0 \pm 4.8$ \\
Waist Circumference $(\mathrm{cm})$ & $93.7 \pm 12.4$ \\
Hypertension & $57.3 \%$ \\
Diabetes & $31.3 \%$ \\
\hline \hline
\end{tabular}

\section{B. Bone Mineral Density of The Study Subjects}

Bone mineral density (BMD) in the lumbar spine and femoral neck is presented in Table II. BMD at lumbar spine was significantly higher than right femoral neck $(\mathrm{p}=0.048)$ and left femoral neck $(\mathrm{p}=0.002)$; BMD at right femoral neck and left femoral neck were similar $(p=0.228)$. Similarly, $T$ score was higher at the lumbar spine than the femoral neck ( $p$ 
$<0.001)$ but similar in the right and left femoral neck ( $\mathrm{p}=$ $0.915)$. Osteoporosis ( $\mathrm{T}$-score $<-2.5$ was found in $58(44.3 \%)$,

TABLE VI: COEFFICIENT OF BMD AND T-SCORE WITH MS IN MULTIPLE REGRESSION ANALYSIS

osteopenia (T-score: -1.0 to $<-2.5) 45(34.4 \%$ ) and normal (Tscore $\geq-1.0) 28(21.3 \%)$ of the study subjects.

TABLE II: BMD IN THE LUMBAR SPINE AND FEMORAL NECK

\begin{tabular}{llc}
\hline \multicolumn{1}{c}{ Area } & BMD $\left(\mathrm{g} / \mathrm{cm}^{2}\right)$ & T-score \\
\hline \hline Lumbar spine & $0.78 \pm 0.17$ & $-2.32 \pm 1.54$ \\
Right femoral neck & $0.75 \pm 0.16$ & $-1.52 \pm 1.29$ \\
Left femoral neck & $0.72 \pm 0.16$ & $-1.53 \pm 1.39$ \\
\hline \hline
\end{tabular}

\begin{tabular}{|c|c|c|c|c|c|c|}
\hline \multirow[b]{2}{*}{$\begin{array}{c}\text { BMD } \\
\left(\mathrm{g} / \mathrm{cm}^{2}\right)\end{array}$} & \multicolumn{2}{|c|}{ Lumbar spine } & \multicolumn{2}{|c|}{ Right femoral neck } & \multicolumn{2}{|c|}{ Left femoral neck } \\
\hline & $\beta$ & $\mathrm{p}$-value & $\beta$ & $\begin{array}{c}\mathrm{p}- \\
\text { value }\end{array}$ & $\beta$ & $\begin{array}{c}\mathrm{p}- \\
\text { value }\end{array}$ \\
\hline logAge & -0.437 & 0.063 & -0.809 & $<0.001$ & -0.567 & 0.006 \\
\hline BMI & 0.016 & $<0.001$ & 0.008 & 0.009 & 0.009 & 0.001 \\
\hline MS & -0.041 & 0.184 & 0.002 & 0.938 & 0.011 & 0.688 \\
\hline T-score & & & & & & \\
\hline logAge & -4.246 & 0.042 & -6.387 & 0.003 & -4.472 & 0.037 \\
\hline BMI & 0.137 & $<0.001$ & 0.066 & 0.005 & 0.007 & 0.843 \\
\hline MS & -0.330 & 0.241 & -0.005 & 0.984 & 0.151 & 0.599 \\
\hline
\end{tabular}

\section{Lipidemic Status of The Study Subjects}

The mean $\pm \mathrm{SD}$ of serum Total cholesterol, Triglycerides, HDL cholesterol, and LDL cholesterol is presented in Table III. Seventy-two $(55.0 \%$ of the study subjects had elevated Triglycerides, and $80.2 \%$ had low HDL cholesterol (Table III).

\begin{tabular}{cc} 
TABLE III: LIPIDEMIC STATUS OF THE STUDY SUBJECTS \\
\hline \hline Variables & Mean \pm SD $/ \%$ \\
\hline \hline Total Cholesterol $(\mathrm{mg} / \mathrm{dL})$ & $185 \pm 38$ \\
Triglycerides $(\mathrm{mg} / \mathrm{dL})$ & $183 \pm 82$ \\
$\geq 150 \mathrm{mg} / \mathrm{dL}$ & $72(55.0 \%)$ \\
HDL cholesterol $(\mathrm{mg} / \mathrm{dL})$ & $43.6 \pm 7.4$ \\
$\leq 50 \mathrm{mg} / \mathrm{dL}$ & $108(80.2 \%)$ \\
LDL cholesterol $(\mathrm{mg} / \mathrm{dL})$ & $105 \pm 35$ \\
\hline \hline
\end{tabular}

\section{Metabolic Syndrome of The Study Subjects}

Eighty-three (63.4\%) of the study subjects have metabolic syndrome (MS), and among the components of metabolic syndrome (MS), proportions of low HDL cholesterol are found to be highest, followed by abdominal obesity, hypertension, high triglycerides and diabetes mellitus (Table IV).

TABLE IV: STATUS OF METABOLIC SYNDROME AMONG THE STUDY SUBJECTS

\begin{tabular}{|c|c|}
\hline Variables & Number $(\%)$ \\
\hline A Abdominal obesity $(\mathrm{WC} \geq 88 \mathrm{~cm})$ & $85(64.9 \%)$ \\
\hline High Triglycerides ( $\geq 150 \mathrm{mg} / \mathrm{dL})$ & $72(55.0 \%)$ \\
\hline HDL cholesterol $(\leq 50 \mathrm{mg} / \mathrm{dL})$ & $108(80.2 \%)$ \\
\hline Hypertension & $75(57.3 \%)$ \\
\hline Diabetes mellitus & $41(31.3 \%)$ \\
\hline
\end{tabular}

\section{E. Multiple Regression Analysis}

The coefficient $(\beta)$ in multiple regression analysis considering BMD at the lumbar spine, right femoral neck or left femoral neck as dependent variable and age, BMI, and MS as independent variables presented in Table V. MS showed no significant association with BMD and T-scores at the lumbar spine and femoral neck (Table VI). Osteoporosis showed a significant positive association with MS in multiple logistic regression analysis considering osteoporosis (T-score $<-2.5$ ) and non-osteoporosis (T-score $\geq-2.5$ ) as dependent variables (Table V).

TABLE V: COEFFICIENT OF OSTEOPOROSIS (T-SCORE <-2.5) WITH MS IN LOGISTIC REGRESSION ANALYSIS

\begin{tabular}{ccc}
\hline \hline Variables & $\beta$ & p-value \\
\hline \hline $\log ($ Age $)$ & 3.224 & 0.321 \\
BMI & -0.173 & $<0.001$ \\
MS (yes) & 1.311 & 0.003 \\
\hline \hline
\end{tabular}

\section{DISCUSSION}

Osteoporosis is common in the elderly, characterized by decreased bone mineral density which increases the risk of fractures, mainly affects the hip, wrist, and spine. In postmenopausal women, estrogen deficiency increases the reduction of bone mineral density (BMD) [24]. Again, postmenopausal women are at risk of developing metabolic syndrome [25]. In this study, the association between BMD and MS was investigated in 131 postmenopausal women of Bangladeshi origin.

In this study, both BMD and T-score were found to be significantly higher in the lumbar spine compared to that in the femoral neck of postmenopausal women. MS was found to be present in higher proportions $(63.4 \%)$ of the study subjects, which is higher than other populations [26], [27] and also higher than the previous study conducted in our population [6], [28]. On multiple regression analysis, we found no significant association of MS with BMD and Tscore. This finding is consistent with the findings of the study conducted in Iranian [29], US [25] and Korean postmenopausal women [30]; several studies reported an association between BMD with the components of MS [26], [29]. However, no association was found between BMD or T-score and the components of MS (data not shown), which is consistent with the finding of the study conducted in the Korean population [30]. In contrast, BMD was found to be inversely associated with MS in another study [14], [15].

In this study, osteoporosis was found to be positively associated with MS in logistic regression analysis. Chen et al. [31] reported a positive association between osteoporosis and MS with non-alcoholic fatty liver in Eastern China in postmenopausal women. However, another study in the elderly population found no association between osteoporosis and MS in males or females [32]. The inconsistency of results among different studies may be related to the number of confounding variables.

\section{ACKNOWLEDGMENT}

This study was supported by The Ministry of Science and Technology (MoST), Bangladesh.

\section{CONCLUSION}

Osteoporosis is positively associated with metabolic syndrome in postmenopausal women, but bone mineral density and T-score are not related to metabolic syndrome. 


\section{REFERENCES}

[1] Ahsan Karar Z, Alam N, Kim Streatfield P. Epidemiological transition in rural Bangladesh, 1986-2006. Glob Health Action. 2009;2.

[2] Misra A, Misra R, Wijesuriya M, Banerjee D. The metabolic syndrome in South Asians: continuing escalation \& possible solutions. Indian $J$ Med Res. 2007; 125(3): 345-354.

[3] World Health Organization. Definition and diagnosis of diabetes mellitus and intermediate hyperglycemia: report of a WHO/IDF consultation. [Internet] 2006. [cited 2020 July 24] Available from: http://www.who.int/diabetes/publications/diagnosis_diabetes2006/en/.

[4] Chowdhury MZI, Anik AM, Farhana Z, Bristi PD, Ābu Al Mamun BM, Uddin MJ, et al. Prevalence of metabolic syndrome in Bangladesh: a systematic review and meta-analysis of the studies. BMC Public Health. 2018; 18: 308.

[5] Park YW, Zhu S, Palaniappan L, Heshka S, Carnethon MR, Heymsfield SB. The metabolic syndrome: prevalence and associated risk factor findings in the US population from the Third National Health and Nutrition Examination Survey, 1988-1994. Arch Intern Med. 2003; 163(4): 427-436.

[6] Jesmin S, Islam AS, Akter S, Islam MM, Sultana SN, Yamaguchi N, et al. Metabolic syndrome among pre- and postmenopausal rural women in Bangladesh: result from a population-based study. BMC Res Notes. 2013; 6: 157 .

[7] Coylewright M, Reckelhoff JF, Ouyang P. Menopause and hypertension: an age-old debate. Hypertension. 2008; 51(4): 952-959.

[8] Lips P, Hosking D, Lippuner K, Norquist JM, Wehren L, Maalouf G, et al. The prevalence of vitamin $\mathrm{D}$ inadequacy amongst women with osteoporosis: an international epidemiological investigation. $J$ Intern Med. 2006; 260(3): 245-254.

[9] Micka AE. Vitamin D status among Bangladeshi women of reproductive age. M.S. Thesis, University of Massachusetts Amherst; 2009.

[10] Islam MZ, Akhtaruzzaman M, Lamberg-Allardt C. Hypovitaminosis D is common in both veiled and nonveiled Bangladeshi women. Asia Pac J Clin Nutr. 2006; 15(1): 81-87.

[11] Islam MZ, Lamberg-Allardt C, Karkkainen M, Outila T, Salamatullah Q, Shamim AA. Vitamin D deficiency: a concern in premenopausal Bangladeshi women of two socio-economic groups in rural and urban region. Eur J Clin Nutr. 2002; 56, 51-56.

[12] Ahlborg HG, Johnell O, Turner CH, Rannevik G, Karlsson MK. Bone loss and bone size after menopause. N Engl J Med. 2003; 349: 327-334.

[13] Park KK, Kim SJ, Moon ES. Association between bone mineral density and metabolic syndrome in postmenopausal Korean women. Gynecol Obstet Invest. 2010; 69(3): 145-152.

[14] Tsuda K, Nishio I, Masuyama Y. Bone mineral density in women with essential hypertension. Am J Hypertens. 2001; 14(7 Pt 1): 704-707.

[15] Cappuccio FP, Meilahn E, Zmuda JM, Cauley JA. High blood pressure and bone-mineral loss in elderly white women: a prospective study. Study of Osteoporotic Fractures Research Group. Lancet. 1999; 354(9183): 971-975.

[16] Kinjo M, Setoguchi S, Solomon DH. Bone mineral density in adults with the metabolic syndrome: analysis in a population-based U.S. sample. J Clin Endocrinol Metab. 2007; 92(11): 4161-4164.

[17] Muraduzzaman SM, Begum S, Ali S, Sultana S, Saiedullah M, Alam F. Association between Bone Mineral Density and Hypertension in Postmenopausal Women. European Journal of Medical and Health Sciences 2021; 3(4): 116-120.

[18] Saiedullah M, Begum S, Muraduzzaman SM, Association of Vitamin B12 with Bone Mineral Density in Postmenopausal Women in Bangladesh. Saudi J Biomed Res. 2021; 6(9): 226-232.

[19] Cosman F, de Beur SJ, LeBoff MS, Lewiecki EM, Tanner B, Randall $\mathrm{S}$, et al. Clinician's Guide to Prevention and Treatment of Osteoporosis [published correction appears in Osteoporos Int. 2015; 26(7): 20452047]. Osteoporos Int. 2014; 25(10): 2359-2381.

[20] World Health Organization. Topics \& Sites, World Health Organization, Geneva, Switzerland, [Internet] 2016. Available from: http://www.who.int/chp/topics/en/http://www.who.int/chp/topics/Oste oporosis.pdf.

[21] Friedewald WT, Levy RI, Fredrickson DS. Estimation of the concentration of low-density lipoprotein cholesterol in plasma, without use of the preparative ultracentrifuge. Clin Chem. 1972; 18(6): 499502.

[22] Tsurusaki K, Ito M, Hayashi K. Differential effects of menopause and metabolic disease on trabecular and cortical bone assessed by peripheral quantitative computed tomography (pQCT). $\mathrm{Br} J$ Radiol. 2000; 73(865): 14-22.

[23] International diabetes federation. The IDF consensus worldwide definition of the metabolic syndrome. [Internet] 2006. [cited 2021 October 21] Available from: https://www.idf.org/e-library/consensus- statements/60-idfconsensus-worldwide-definitionof-the-metabolicsyndrome.

[24] Riggs BL, Khosla S, Melton LJ 3rd. A unitary model for involutional osteoporosis: estrogen deficiency causes both type I and type II osteoporosis in postmenopausal women and contributes to bone loss in aging men. J Bone Miner Res. 1998; 13(5): 763-773.

[25] Kim HM, Park J, Ryu SY, Kim J. The effect of menopause on the metabolic syndrome among Korean women: the Korean National Health and Nutrition Examination Survey, 2001. Diabetes care, 2007; 30: 701-706.

[26] Muka T, Trajanoska K, Kiefte-de Jong JC, Oei L, Uitterlinden AG, Hofman A, et al. The Association between Metabolic Syndrome, Bone Mineral Density, Hip Bone Geometry and Fracture Risk: The Rotterdam Study. PLoS One. 2015; 10(6): e0129116.

[27] Marias S. The association between the metabolic syndrome and bone mineral density in pre-and postmenopausal farm workers. MS Thesis, University of Stellenbosch; 2016.

[28] Jahan MS, Billah MB. Metabolic Syndrome in Bangladeshi Menopausal Women. Banagladesh Coll Phys Surg. 2016; 34: 15-20.

[29] Abourazzak F, Essouiri J, Lazrak F, Azzouzi H, Keita S. Metabolic Syndrome and Bone Mineral Density in Post-Menopausal Women: Is There Any Link? J Rheumatol Arthritic Dis. 2016; 1 :1-7.

[30] Kim SH, Kim J. The Relationship between Risk Factors for Metabolic Syndrome and Bone Mineral Density in Menopausal Korean Women. Iran J Public Health. 2019; 48(6): 1025-1032.

[31] Chen DZ, Xu QM, Wu XX, Cai C, Zhang LJ, Shi KQ, et al. The Combined Effect of Nonalcoholic Fatty Liver Disease and Metabolic Syndrome on Osteoporosis in Postmenopausal Females in Eastern China. Int J Endocrinol. 2018; 2018: 2314769.

[32] Lin HH, Huang CY, Hwang LC. Association between metabolic syndrome and osteoporosis in Taiwanese middle-aged and elderly participants. Arch Osteoporos. 2018; 13(1): 48. 